\title{
A SMALL SIZE WIND GENERATION SYSTEM FOR BATTERY CHARGING
}

\author{
Isaac R. Machado, Demercil de S.O. Jr., Luiz H. S. C. Barreto, Herminio M. de O. Filho \\ Federal University of Ceará - Group of Energy Processing and Control - GPEC \\ PO Box 6001, CEP-60455-760, Tel.: +55 (85) 3366-9586, Fortaleza-CE - Brazil \\ isaacrochamachado@yahoo.com.br, demercil@dee.ufc.br
}

\begin{abstract}
This paper is concerned with the study of a small wind generation system used for battery charging. A topology that aims at the exploitation of the energy generated at low speed is proposed. The characteristics of the wind turbine and the generator are discussed, providing the overview of the system modeling. Simulation tests of the system are obtained using MATLAB/SIMULINK, as the relevant results are supposed to be compared with experimental data and validate the proposal.
\end{abstract}

Keywords - Battery charging, maximum power point operation, wind generation.

\section{NOMENCLATURE}

B Coefficient of viscous friction $(0.00467 \mathrm{Nm} / \mathrm{rad} / \mathrm{s})$;

$\boldsymbol{J}$ Inertia moment $\left(J=0.065 \mathrm{~kg} \cdot \mathrm{m}^{2}\right)$;

$\boldsymbol{P} \quad$ Number of pole pairs $(P=7)$;

Te Electrical torque;

$\boldsymbol{T}_{\boldsymbol{m}} \quad$ Mechanical torque;

$\boldsymbol{\rho}$ Differential operator;

$\boldsymbol{\theta}_{g} \quad$ Angle that defines the mechanical position of the rotor $(\mathrm{rad})$;

$\boldsymbol{\theta}_{\boldsymbol{r}} \quad$ Angle that defines the electrical position of the rotor (rad).

\section{INTRODUCTION}

A wind generation system can be used basically in three distinct applications: isolated systems, hybrid systems, and grid connected systems. Basic characteristics of the systems include a power stage and energy storage capability. Generally, small size isolated systems demand energy storage, by the use of batteries or in the form of gravitational potential energy in order to store the water pumped in reservoirs raised for posterior use. Some isolated systems do not need storage, as in the case of systems for irrigation where all the pumped water directly is consumed.

This paper deals in particular with the study of a wind generation system for battery charging. The complete analysis of the system is presented, and an alternative of optimum control at low speeds so that the extraction of energy occurs in a wide range of wind speedy is also described.

\section{PROPOSED TOPOLOGY}

\section{A. Power Circuit}

The studied system is available commercially and manufactured by ENERSUD [4]. It is composed of a wind turbine directly connected to a permanent magnet synchronous generator (without gear box), and a battery charger. Nowadays this system is available with the absence of the charging controller, what reduces the useful life of the batteries and does not support the operation at low speed. This limitation is indeed due to the connection of two batteries in series $(24 \mathrm{~V})$ fed directly by a three-phase rectifier. Therefore the presence of diodes does not allow the energy transfer while the induced voltage does not exceed the battery voltage, what corresponds to approximately 240rpm.

To solve these problems, a new topology is proposed, where a boost converter operates in parallel with a threephase bridge rectifier. At low speed, the boost converter is used to draw the current from the generator to the batteries. When voltage $\boldsymbol{V}_{\boldsymbol{d} \boldsymbol{} \boldsymbol{}}$ (Fig. 1) is greater than $24 \mathrm{~V}$ (high speed operation), the rectifier starts supplying energy directly to the batteries, as the converter is not operating.

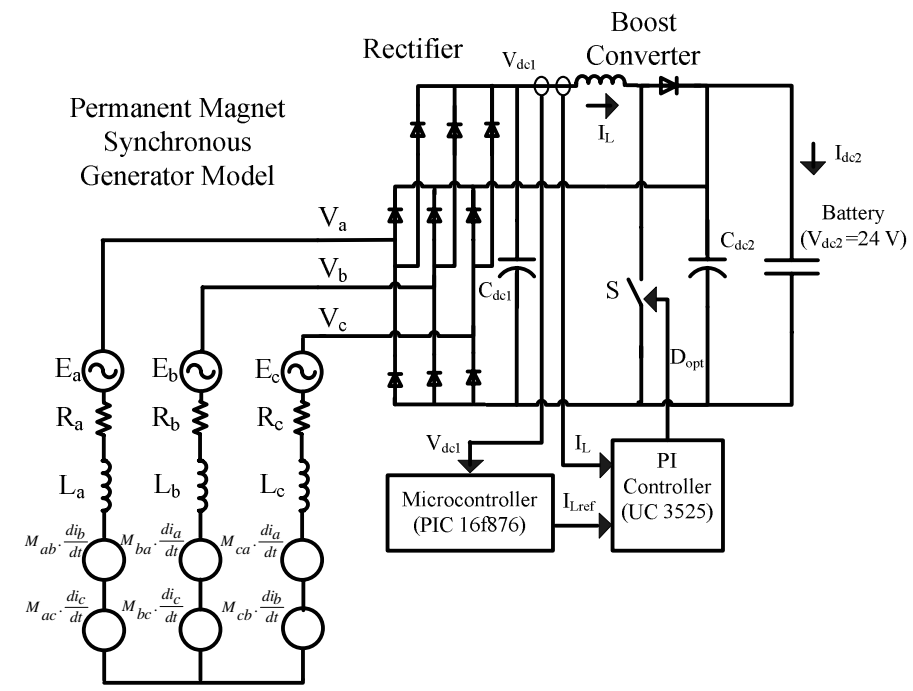

Fig. 1. Proposed topology.

\section{B. Control Technique}

The measurement of voltage $\boldsymbol{V}_{\boldsymbol{d c l}}$ is necessary for the calculation of reference current $\boldsymbol{I}_{\text {Lref }}$, used in the average current mode control, and also PWM control performed by IC UC3525. The reference current values are summarized in a table that determines optimum values for voltage $V_{d c l}$ and the mechanical speed.

\section{SYSTEM MODELING}

\section{A. Wind Turbine Performance}

An amount of wind mass $\boldsymbol{m}$ and density $\boldsymbol{\rho}_{\boldsymbol{a}}$ that flows with speed $\boldsymbol{u}$ in the axial direction of the wind turbine has some kinetic energy. The available wind power $\boldsymbol{P}_{\boldsymbol{v}}$ is the derivative of the kinetic energy with regard to time, given by equation (1): 


$$
P_{v}=\frac{1}{2} \cdot \rho_{a} \cdot A_{v} \cdot u^{3}
$$

The extracted mechanical power $\boldsymbol{P}_{\boldsymbol{m}}$ from the available wind power $\boldsymbol{P}_{\boldsymbol{v}}$ is determined by the power coefficient $\boldsymbol{C}_{\boldsymbol{p}}$, according to equation (2).

$$
P_{m}=C_{p} \cdot P_{v}=C_{p} \cdot\left(\frac{1}{2} \cdot \rho_{a} \cdot A_{v} \cdot u^{3}\right)
$$

The performance of the power coefficient of wind turbines is determined by manufacturers through tests carried out in wind tunnels. The value of $\boldsymbol{C}_{\boldsymbol{p}}$ is a function of the wind speed $\boldsymbol{u}$, rotation speed of the turbine $\boldsymbol{\omega}_{g}$, pitch angle $\boldsymbol{\beta}$, and the aerodynamic characteristics of the turbine.

The curve of the power coefficient for a given wind turbine is presented in equation (3):

$$
C_{p}=C_{1} \cdot\left(\frac{C_{2}}{\lambda_{i}}-C_{3} \cdot \beta-C_{4}\right) \cdot e^{\frac{C_{5}}{\lambda_{i}}}+C_{6} \cdot \lambda
$$

where $\lambda_{i}$ is a parameter given in (4).

$\frac{1}{\lambda_{i}}=\frac{1}{\lambda+0.08 . \beta}-\frac{0.035}{\beta^{3}+1}$

In the simulation tests, the following values for the constants mentioned in equation ( 3 ) are considered:

$\mathrm{C}_{1}=0.5176, \mathrm{C}_{2}=116, \mathrm{C}_{3}=0.40, \mathrm{C}_{4}=5, \mathrm{C}_{5}=21, \mathrm{C}_{6}=0.0068$

These values are given for a three-bladed wind turbine, with similar aerodynamic characteristics to the turbine used in the system. The value of $\boldsymbol{\beta}$ chosen for simulation is $0^{\circ}$, as the maximum $\boldsymbol{C}_{\boldsymbol{p}}$ is obtained in this condition.

\section{B. Generator Characteristics}

The electrical machine used in the system is a permanent magnet synchronous generator (PMSG) rated at $1 \mathrm{~kW}, 1000$ rpm, 7 pole pairs and axial flux. This type of machine is particularly interesting for applications in wind generation due to its inherent characteristics. Several studies such as those in [2] deal with the characteristics of this machine. The dynamic model of the machine is obtained in [3], described by expressions (5) to (8).

$$
\begin{aligned}
& T_{e}=\frac{E_{a} \cdot I_{a}+E_{b} \cdot I_{b}+E_{c} \cdot I_{c}}{\omega_{g}} \\
& J \cdot \rho \cdot \varpi_{g}=T_{m}-T_{e}-B \cdot \varpi_{g} \\
& \rho \cdot \theta_{g}=\omega_{g} \\
& \rho \cdot \theta_{r}=P \cdot \omega_{g}
\end{aligned}
$$

The electrical model of the synchronous machine in steady-state operation as a generator is shown in Fig. 2 [5]. To determine the physical parameters of the machine such as phase resistance, self-inductance and mutual inductance, several evaluation tests are performed as in [2]. The values considered in the simulation are $0.5 \Omega /$ phase (resistance), $3.35 \mathrm{mH}$ (self-inductance) and $3.06 \mathrm{mH}$ (mutual inductance).

\section{SYSTEM SIMULATION}

The system modeling is obtained considering the expressions presented in the previous session. Simulation tests are performed using MATLAB/SIMULINK as shown in Fig. 2.

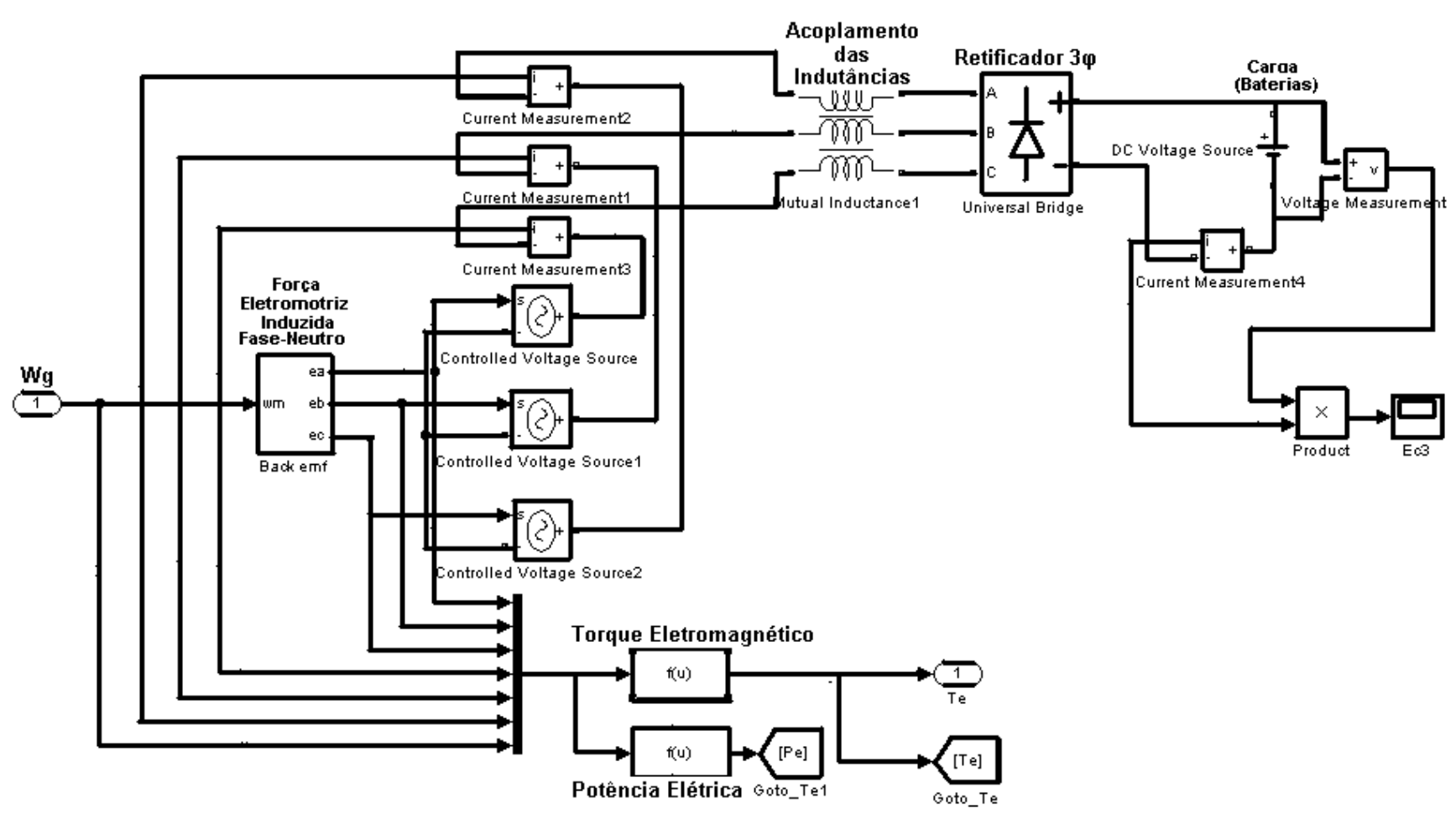

Fig. 2. Matlab model of the generator. 


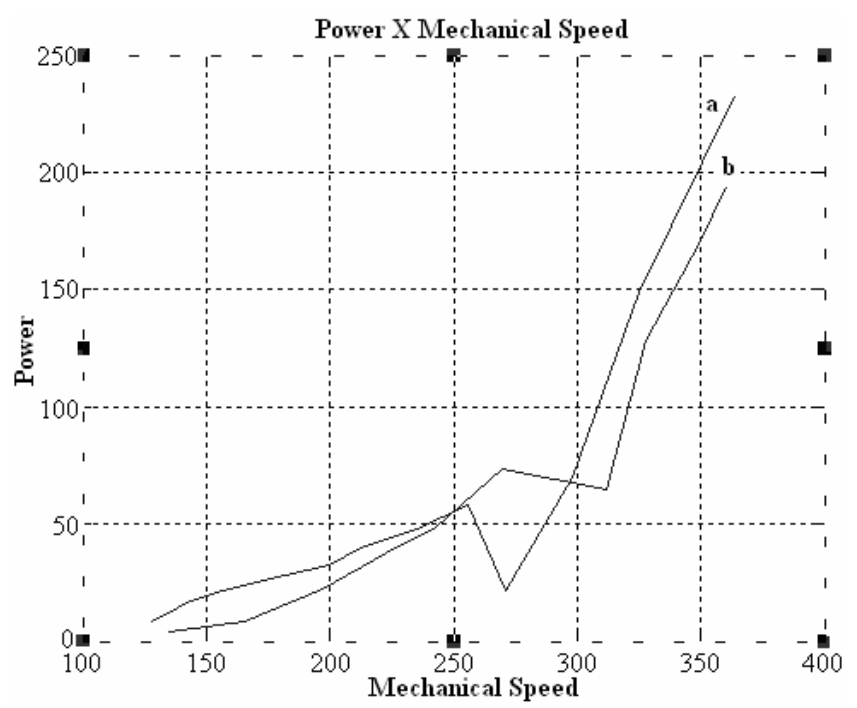

Fig. 3. Output Power Versus Mechanical Speed ( $\mathrm{a}$ - simulated, $\mathrm{b}$ - experimental).

In a first moment several simulation tests were performed, considering the batteries directly connected to the output of the three-phase rectifier. Fig. 3 shows the curves obtained by experimental measurements and by simulation, validating the developed model. In Table I one can see some simulation results for several wind speeds.

After that, several simulations were performed using a controlled voltage source connected to the output of the three-phase rectifier. The controlled voltage is linearly increased from zero. Fig. 4 shows the measured output power. It can be seen that there is an optimum point $(\mathrm{t}=6.25 \mathrm{~s})$, what causes a maximum output power. In Fig. 5 one can see that maximum $\boldsymbol{C}_{\boldsymbol{p}}$ occurs in a different point $(t=5 s)$, due to the generator internal losses.

TABLE I

Simulation Results for Constant Voltage $V_{d c 1}\left(V_{d c 1}=24 \mathrm{~V}\right)$

\begin{tabular}{|c|c|c|c|c|c|c|c|}
\hline$\underset{(\mathbf{m} / \mathbf{s})}{\mathbf{u}}$ & $\begin{array}{l}\mathbf{V}_{\text {dc1 }} \\
(\mathbf{V})\end{array}$ & $\begin{array}{l}\mathbf{P}_{\mathrm{dc1}} \\
(\mathbf{W})\end{array}$ & $\begin{array}{l}\mathbf{I}_{\text {dc1 }} \\
(\mathbf{A})\end{array}$ & $\begin{array}{c}\omega_{\mathrm{g}} \\
(\mathbf{r p m})\end{array}$ & Cp & $\begin{array}{c}\mathbf{I}_{\text {ef }} \\
(\mathbf{A})\end{array}$ & $\begin{array}{c}\mathbf{I}^{2} \mathbf{R} \\
\text { Loss } \\
(\mathrm{W})\end{array}$ \\
\hline 3 & 24.0 & 21.6 & 0.9 & 271 & 0.181 & 0.75 & 0.84 \\
\hline 4 & 24.0 & 69.6 & 2.9 & 298 & 0.474 & 2.4 & 8.28 \\
\hline 5 & 24.0 & 149 & 6.2 & 325 & 0.471 & 4.9 & 36.75 \\
\hline 6 & 24.0 & 233 & 9.7 & 364 & 0.479 & 7.8 & 91.26 \\
\hline 7 & 24.0 & 326 & 13.6 & 405 & 0.479 & 10.8 & 174.96 \\
\hline 8 & 24.0 & 437 & 18.2 & 450 & 0.476 & 14.5 & 315.37 \\
\hline 9 & 24.0 & 564 & 23.5 & 501 & 0.479 & 18.6 & 518.94 \\
\hline 10 & 24.0 & 699 & 29.1 & 558 & 0.472 & 23.2 & 807.36 \\
\hline
\end{tabular}

TABLE II

Simulation Results for Maximum Power Point Operation.

\begin{tabular}{|c|c|c|c|c|c|c|c|}
\hline$\underset{(\mathbf{m} / \mathbf{s})}{\mathbf{u}}$ & $\begin{array}{c}\text { Opti } \\
\text { mum } \\
\mathbf{V}_{\text {dc1 }} \\
(\mathrm{V})\end{array}$ & $\begin{array}{l}\mathbf{P}_{\text {dc1 }} \\
(\mathbf{W})\end{array}$ & $\begin{array}{l}\mathbf{I}_{\mathrm{dc1}} \\
(\mathbf{A})\end{array}$ & $\begin{array}{c}\omega_{\mathrm{g}} \\
(\mathbf{r p m})\end{array}$ & Cp & $\begin{array}{c}\mathbf{I}_{\mathrm{ef}} \\
(\mathbf{A})\end{array}$ & $\begin{array}{c}\mathbf{I}^{2} \mathbf{R} \\
\text { LoSS } \\
(\mathbf{W})\end{array}$ \\
\hline 3 & 21.0 & 36.75 & 1.70 & 208 & 0.447 & 1.57 & 3.69 \\
\hline 4 & 26.3 & 86.62 & 3.30 & 271 & 0.458 & 2.90 & 12.61 \\
\hline 5 & 31.0 & 164.3 & 5.30 & 333 & 0.454 & 4.40 & 29.04 \\
\hline 6 & 37.3 & 272.6 & 7.30 & 409 & 0.430 & 6.40 & 61.44 \\
\hline 7 & 44.1 & 413.6 & 9.30 & 493 & 0.448 & 7.65 & 87.78 \\
\hline 8 & 47.2 & 604.1 & 12.8 & 554 & 0.439 & 10.3 & 160.68 \\
\hline 9 & 53.0 & 829.4 & 15.6 & 636 & 0.437 & 12.5 & 234.37 \\
\hline 10 & 57.0 & 1100.1 & 19.3 & 708 & 0.432 & 15.2 & 360.37 \\
\hline
\end{tabular}

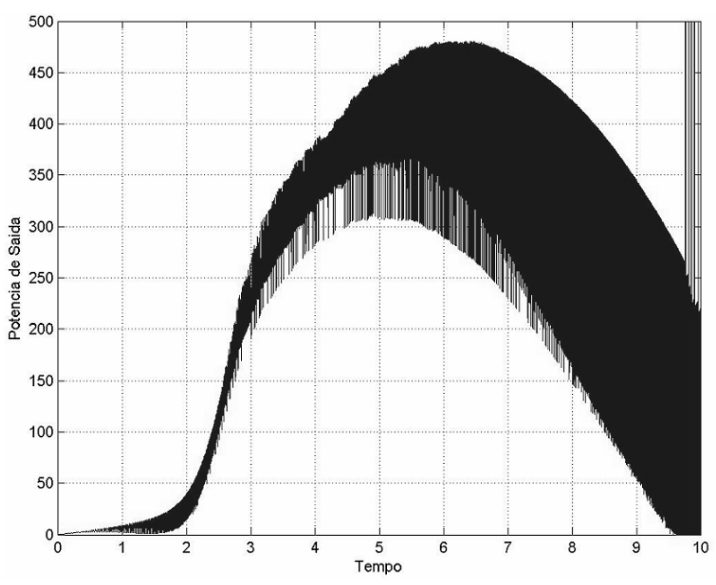

Fig. 4. Output power versus time.

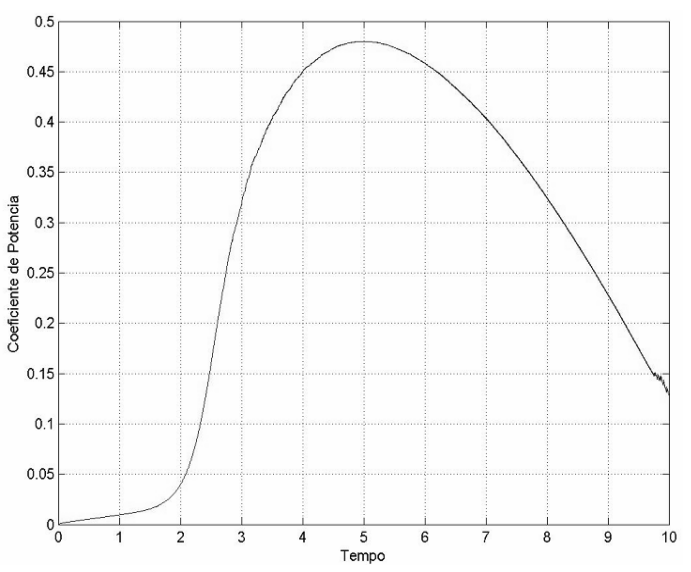

Fig. 5. Power coefficient $\mathrm{C}_{\mathrm{p}}$ as a function of time.

A comparison between the obtained output power in Tables I and II shows that the directly coupling between the three-phase rectifier and the batteries does not make use of the complete available wind energy. Also, for low wind speeds, the induced line voltage is not enough to bias the rectifier diodes.

\section{EXPERIMENTAL RESULTS}

As the proposed converter was introduced in order to improve the power generation at low wind speeds, experimental results were measured up to a maximum mechanical speed equal to $366 \mathrm{rpm}$ The dc-dc converter becomes inoperative when voltage $\boldsymbol{V}_{d c 1}$ reaches $25 \mathrm{~V}$ and, then the batteries are fed directly by the rectifier.

TABLE III

Experimental Results for Low Speeds Operation .

\begin{tabular}{llllllll}
\hline $\begin{array}{l}\omega_{\mathrm{g}} \\
(\mathbf{r p m})\end{array}$ & $\begin{array}{l}\mathbf{V}_{\text {line }} \\
(\mathbf{V})\end{array}$ & $\begin{array}{l}\mathbf{I}_{\text {line }} \\
(\mathbf{A})\end{array}$ & $\begin{array}{l}\mathbf{P}_{\text {dc1 }} \\
(\mathbf{W})\end{array}$ & $\begin{array}{l}\mathbf{V}_{\mathbf{d c 2}} \\
(\mathbf{V})\end{array}$ & $\begin{array}{l}\mathbf{I}_{\mathbf{d c 2}} \\
(\mathbf{A})\end{array}$ & $\begin{array}{l}\mathbf{I}_{\mathbf{L}} \\
(\mathbf{A})\end{array}$ & $\begin{array}{l}\mathbf{V}_{\text {dc1 }} \\
(\mathbf{V})\end{array}$ \\
\hline 155 & 12 & 0.4 & 6.5 & 24.58 & 0.3 & 0.55 & 14.6 \\
174 & 13.3 & 0.71 & 13.1 & 24.66 & 0.55 & 0.85 & 16 \\
205 & 15.3 & 1.16 & 25.9 & 24.82 & 0.95 & 1.43 & 18.3 \\
225 & 16.5 & 1.65 & 41 & 25 & 1.5 & 2.01 & 20.1 \\
254 & 18.2 & 2.19 & 62 & 25.27 & 2.15 & 2.74 & 21.9 \\
285 & 19.8 & 3.1 & 93 & 25.63 & 3.2 & 3.73 & 24.2 \\
\hline
\end{tabular}

Table III shows the measured values at low speed. The extraction of power at low speeds is observed, what does not occur when the rectifier is directly connected to the batteries. Fig. 6 shows the efficiency as a function of the output power. 


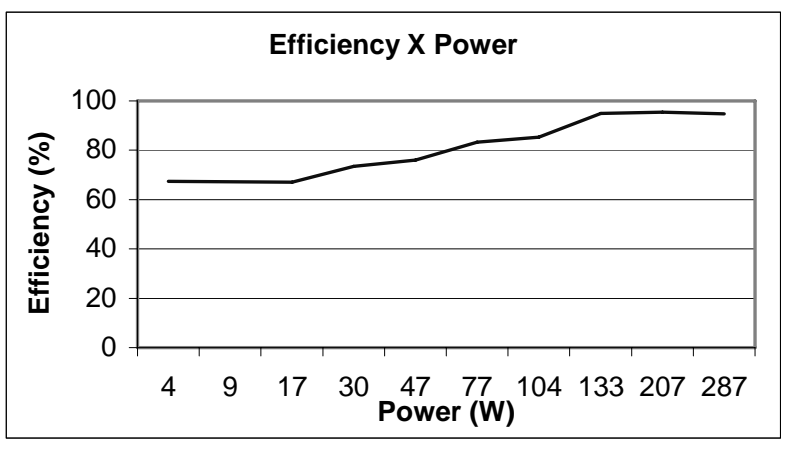

Fig. 6. Efficiency as a function of the output power.

Figs 7 to 9 show some results for mechanical speed equal to $182 \mathrm{rpm}$. In Fig. 7 , the behavior of the line current and phase voltage is given. The rms voltage is approximately $8.5 \mathrm{~V}$ and the current is $1.25 \mathrm{~A}$. The apparent power is $31.87 \mathrm{VA}$ and the active power is $25.5 \mathrm{~W}$, while power factor is $0.8 \mathrm{lag}$. The presence of noise in the voltage waveforms shown in Figs. 6 and 7 are due to the switching elements in the boost converter.

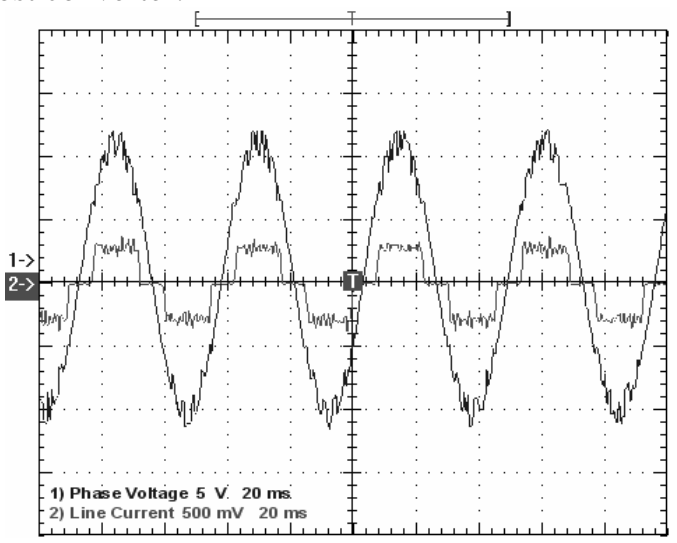

Fig. 7. Phase voltage and line current for $\omega_{g}=182 \mathrm{rpm}(2.5 \mathrm{~A} / \mathrm{div}$, $5 \mathrm{~V} / \mathrm{div}, 20 \mathrm{~ms} / \mathrm{div})$.

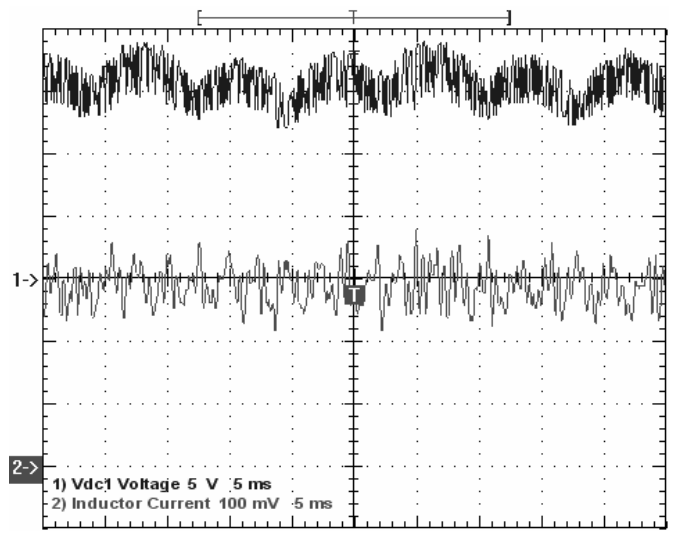

Fig. 8. Voltage $\boldsymbol{V}_{\boldsymbol{d} \boldsymbol{} \boldsymbol{l}}$ and current through inductor $\boldsymbol{I}_{\boldsymbol{L}}$ for $\boldsymbol{\omega}_{g}=182 \mathrm{rpm}$ $(0.5 \mathrm{~A} / \mathrm{div}, 5 \mathrm{~V} / \mathrm{div}, 5 \mathrm{~ms} / \mathrm{div})$.
The current through the battery bank $\boldsymbol{I}_{d c 2}$ has the behavior shown in Fig. 8. The average value is $0.9 \mathrm{~A}$, and the output power is $22 \mathrm{~W}$. For this situation, efficiency is $87 \%$.

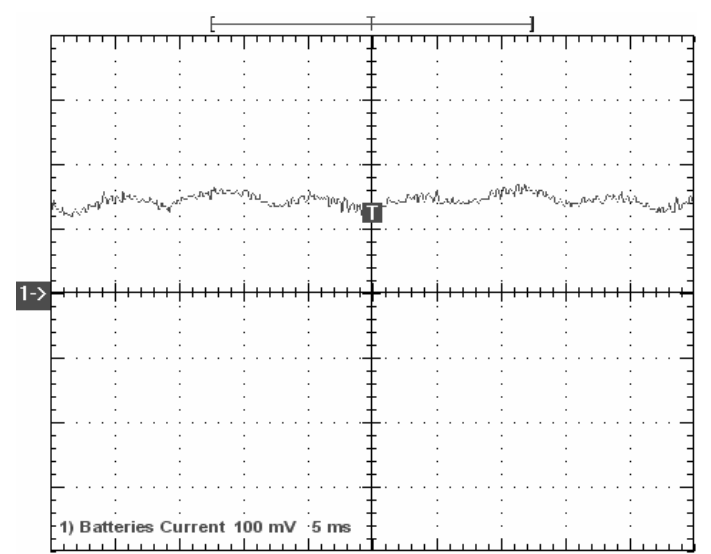

Fig. 9. Current through the battery bank $\boldsymbol{I}_{d c 2}$ for $\omega_{g}=182 \mathrm{rpm}$ $(0.5 \mathrm{~A} / \mathrm{div}, 5 \mathrm{~V} / \mathrm{div}, 5 \mathrm{~ms} / \mathrm{div})$.

\section{CONCLUSIONS}

A new topology used in wind systems for battery charging has been proposed in this paper. A simulation of the complete system has also been implemented and discussed. The validation of the simulation model is obtained from the comparison between the simulated and experimental results. It has been verified the existence of an optimum point for the system operation according to the wind speed.

With the proposed topology, the extraction of power at low speeds is evidenced by the experimental results what improves the system performance. Then it can be considered more attractive than that presented by manufacturer ENERSUD.

\section{REFERENCES}

[1] Tomohiko Nakamura, Shigeo Morimoto, Masayuki Sanada, Yoji Takeda, "Optimum Control of IPMSG for Wind Generation System”, Department of Electrical and Electronic Systems Osaka Prefecture University. (Presented PCC-Osaka 2002), pp. 1435-1440.

[2] B.J. Chalmers, A.M. Green, A.B.J. Reece, A.H. Al-Badi, "Modeling and Simulation of the Torus Generator.", IEE Proceedings online no. 19971429.

[3] A.H. Al-Badi and A. Gastli, "MATLAB and PSPICE Dynamic Model of Axial-Field Permanent-Magnet." , Department of Electrical Engineering, College of Engineering, Sultan Qaboos University, P.O. Box 33, AllKhod 123, Muscat, Sultanate of Oman, Science and Technology, 7 (2002) 109-121.

[4] www.enersud.com.br 